Никитина В.A

\title{
НАЁМ ЖИЛЫХ ПОМЕЩЕНИЙ ГРАЖДАНАМИ, ИМЕЮЩИМИ НИЗКИЙ УРОВЕНЬ ДОХОДОВ И НУЖДАЮЩИМИСЯ В ЖИЛЫХ ПОМЕЩЕНИЯХ, В ПРАВЕ РОССИИ И ГЕРМАНИИ
}

\begin{abstract}
Аннотация: Статья посвящена особенностям правового регулирования найма жилых помещений, как одного из способов реализации права на жилище гражданами, имеющими низкий уровень доходов, в России и в Германии. Анализируется развитие в России и в Германии института найма жилья, а также договоры найма жильх помещений с гражданами, имеющими низкий уровень доходов и нуждающимися в жилых помещениях, предусмотренные российским и германским правом. Особое внимание уделяется условиям, предъявляемым в России и в Германии для заключения таких договоров. Методологической основой данного исследования является использование методов сравнительно-правового, формально-юридического, а также логического анализа. Несмотря на большую актуальность (получение сочиального жилья по договору найма жилого помещения для миллионов людей как в России, так и в Германии является оптимальным вариантом решения жилищной проблемы), данная тема практически не исследована в отечественной научной литературе. Автором выделяются основные отличия, имеющиеся в законодательстве России и Германии, регулирующем наём жилых помещений с гражданами, имеющими низкий уровень доходов, а также делается вывод о возможности использования опыта Германии в совершенствовании российского законодательства в данной сфере.
\end{abstract}

Ключевые слова: Договор сочиального найма, договор найма жилья, некоммерческий наём, социальное жильё, право на жилище, малоимущие, потребность в жилье, жилищный наём Германии, наёмная плата, низкий уровень дохода.

Abstract: This article is dedicated to the peculiarities of the legal regulation of rent of residential properties as one of the means of realization of the right to housing by citizens with low income in Russia and Germany. Analysis is conducted on the development of the institution of renting in Russia and Germany, as well as rental agreements of low income citizens with the right to a place to live as established by the Russian and German legislations. A special attention is given to the conditions given in Russia and Germany for signing such agreements. Despite the great relevance (government housing based on a rental agreement for millions of people in Russia and Germany remains an optimal option for solving residence issue), this topic is practically untouched by researchers in Russian scientific literature. The author highlights main distinctions in the Russian and German legislations that regulate rent of residential properties, and makes a conclusion on the possibility of using German experience for the purpose of improving Russian legislation in this area.

Keywords: Housing need, low income citizens, right to housing, social housing, noncommercial lease, residential lease agreement, social housing lease agreement, German social lease, rent, low income level.

а современном этапе в Российской Федерации приобретение жилья гражданином, имеющим низкий уровень дохода, даже на льготных условиях, является крайне затруднительным. Наём жилья по рыночной стоимости, принимая во внимание соотношение размера наёмной платы и средний заработок граждан, также нельзя назвать доступным для всех категорий населения [7].

Важность поддержки лиц, не имеющих достаточных средств на приобретение жилья, подчеркивалась ещё в 1991 году Комитетом ООН по экономическим, социальным и культурным правам, который указал, что право на жилище, закрепленное в ст. 11 Международного пакта об экономических, социальных и культурных правах от 16 декабря 1966 года, включает в себя доступность жилья (в т.ч. арендуемого) с точки зрения расходов, поэтому государства должны предпринимать меры с тем, чтобы расходы человека на жильё были соразмерны размеру доходов, а также оказывать поддержку тем, кто не имеет достаточно средств на приобретение жилья [22].

В Российской Федерации, как в социальном государстве, лицам, находящимся в тяжелом материальном положении, предоставляются особые гарантии в данной сфере. В Конституции Российской Федерации [13], устанавливающей в ст. 40 право на жилище, указывается, что малоимущим и иным указанным в законе гражданам, нуждающимся в жилище, оно «предоставляется бесплатно или за доступную плату из государственных, муниципальных и других жи- 
лищных фондов в соответствии с установленными законом нормами». В п. 3 ст. 2 Жилищного кодекса Российской Федерации [6] (далее - ЖК РФ) конкретизируется, что органы государственной власти и органы местного самоуправления в установленном порядке предоставляют гражданам жилые помещения по договорам социального найма или договорам найма жилых помещений государственного или муниципального жилищного фонда. Кроме того, по договору найма жилого помещения жилищного фонда социального использования (так называемого «некоммерческого найма»), предусмотренного в разделе 8.1 ЖК РФ, особым категориям граждан в пользование может быть передано жильё жилищного фонда социального использования, куда относится и частный жилищный фонд. Таким образом, в настоящее время в России социальное жильё может передаваться в пользование гражданам по договору найма жилых помещений (ст. 671 Гражданского кодекса РФ [4] (далее - ГК РФ)) и договору найма жилого помещения в жилищном фонде социального использования (ст. 672 ГК РФ), к которому относятся договоры социального и некоммерческого найма .

Несмотря на различные правовые конструкции по поддержке граждан в жилищной сфере, обеспеченность граждан наёмным социальным жильём по-прежнему, не высока. По некоторым данным, в России на учете в качестве нуждающихся в жилых помещениях стоят 5 \% от общего числа семей [5].

С тем чтобы развивать социальную направленность Российской Федерации в сфере регулирования договоров найма жилых помещений с лицами, имеющими низкий уровень доходов, целесообразно проанализировать опыт экономически развитых стран, например, Германии, в которой сложились свои особенности найма социального жилья.

Говоря об истории развития в России и Германии договоров найма жилых помещений, следует отметить, что они в законодательстве двух стран долгое время отсутствовали, а наём жилья регулировался общими нормами об имущественном найме. С середины XX века в России наметилась тенденция выделения договора найма жилья в самостоятельный институт. Впервые нормы о найме жилого помещения в виде отдельной главы вошли в Основы гражданского законодательства СССР 1961 года, а затем в Гражданский кодекс РСФСР 1964 года, в которых выделялось два вида отношений по найму жилья: договор найма жилого помещения в домах государственного и общественного жилищного фонда и договор найма жилого помещения в домах, принадлежащих гражданам на праве личной собственности. Конституционная норма о праве граждан на жилище появилась позднее, в Конституции СССР 1977 года (ст. 44), а затем в Конституции РСФСР 1978 года (ст. 42), которая, среди прочего предписывала справедливое распределение под общественным контролем жилой площади, предоставляемой по мере осуществления программы строительства благоустроенных жилищ, а также невысокую плату за квартиру и коммунальные услуги.

В Германии же впервые право на жилище было закреплено в ст. 155 Веймарской конституции 1919 года, в которой была поставлена цель по обеспечению каждого гражданина здоровым жильём. В действующем Основном законе ФРГ 1949 года право на жилище прямо не предусмотрено, однако, его наличие вытекает из ст. 20 Основного закона ФРГ 1949 года, в которой Германия провозглашается социальным государством [18]. Кроме того, в большинстве конституций земель ФРГ в той или иной форме закрепляется право на жилище [21], при этом, в некоторых из них имеются нормы о социальном жильё (напр., Баварии, Мекленбурга-Передней Померании, Бранденбурга), а также о необходимости оказывать со стороны земли поддержку в получении достаточного жилья лицами, имеющими низкий уровень доходов (Берлин).

До вступления в силу с 1 сентября 2001 года Закона о реформе жилищного законодательства, положения о найме жилых помещений отдельно в Германском гражданском уложении от 18 августа 1896 года [2] (далее - ГГУ) не выделялись, применялись общие нормы об имущественном найме и, если не было установлено иное, нормы о найме земельных участков (§ 580 ГГУ в редакции действующей до 31 августа 2001 года). Хотя социальное жильё появилось в Германии уже в 20-х годах XX века, какие-либо нормы о его передаче в гражданском законодательстве того времени специально не предусматривались. С 50-х годов XX века в Федеративной Республики Германии и Германской Демократической Республике параллельно принимались специальные законы о найме жилья, плата за которое могла быть доступна для широких слоёв населения. Интересно отметить, что в двух Конституциях ГДР 1949 и 1968 годов закреплялись гарантии граждан на жильё, а значительное количество норм советского права, касавшихся найма социального жилья, было воспринято правом ГДР.

В настоящее время в Российской Федерации наём жилых помещений регулируется как гражданским, так и жилищным законодательством. Обязательства из договора найма жилого помещения (так называемый «договор коммерческого найма») регулируются преимущественно ГК РФ (гл. 35), а из договоров найма жилого помещения жилищного фонда социального 
использования главным образом - ЖК РФ (раздел III и III.1). Гражданское законодательство регламентируется исключительной компетенцией Российской Федерации (п. о) ст. 71 Конституции РФ), а жилищное относится к сфере совместной компетенции РФ и её субъектов (пп. к) п. 1 ст. 72 Конституции РФ и п. 1 ст. 5 ЖК РФ), что обуславливает возможность субъектов РФ принимать собственные акты в сфере найма жилья с лицами, относящимися к социально незащищённой категории. Такое разделение на отрасли законодательства привело к различным мнениям среди цивилистов относительно соотношения упомянутых договоров: являются ли они разновидностью договора найма жилого помещения или представляют собой самостоятельные виды договоров. Так, Е.А. Суханов считает, что речь идет о различных договорных формах удовлетворения жилищных потребностей граждан ввиду того, что договор социального найма представляет собой лишь гражданско-правовое оформление административных актов распределения жилья, объективно обусловленных его нехваткой и дороговизной, в то время как коммерческий наём является классической разновидностью акта товарообмена, оформляемого традиционным гражданско-правовым договором [19, с. 389]. В отношении договоров коммерческого и социального найма М.И. Брагинский также отмечал, что в главе «Наем жилых помещений» ГК РФ содержатся два самостоятельных типа договора [1, с. 647]. По мнению С.А. Хохлова договор найма жилого помещения - это общий тип договора для двух его разновидностей: договора коммерческого найма и договора социального найма [3, с. 243-244]. Такой же точки зрения придерживаются и другие правоведы (например, П.В. Крашенинников [15], П.И. Седугин $[20$, c. 89]), признающие договор коммерческого найма и договор социального найма разновидностями договора найма жилого помещения.

Ввиду того, что указанные договоры оформляют отношения по найму жилья, в их определении имеется много общего: по ним наймодатель обязуется предоставить нанимателю за плату жилое помещение во владение и пользование для проживания в нём. Дополнительные условиях устанавливаются нормами, применимыми к соответствующему договору. Важно отметить, что поскольку особенностью договора жилищного найма является его целевой характер, помещение предоставляется исключительно для проживания в нём, соответственно, в качестве нанимателя выступают только граждане [12].

Договор сочиильного найма жилого помещения, введенный в российское законодательство с принятием Жилищного кодекса с 1 марта 2005 года, и договор найма жилого помещения жилищного фонда сочиального использования, включенный в ЖК РФ в 2014 году, являются договорами, по которым жильё предоставляется гражданам, признанным нуждающимися в жилых помещениях и относящимся к определенным социально незащищенным категориям лиц, в том числе к тем, которые исходя из своего тяжелого финансового положения не могут самостоятельно приобрести жилье (малоимущие и иные граждане).

Для заключения лицами, имеющими низкий уровень доходов, данных договоров необходимо наличие определенных административно-правовых предпосылок таких как принятие гражданина на учёт в качестве нуждающегося в жилом помещении и вынесение решения органа местного самоуправления о предоставлении гражданину, состоящему на учёте, жилого помещения по соответствующему договору.

В качестве общих оснований (как для социального, так и некоммерческого найма), необходимых для принятия лица на учет в качестве нуждающегося в жилом помещении, можно выделить следующие:

а). наличие российского гражданства (ч. 5 ст. 49, ч. 1 ст. 91.3 ЖК РФ);

б). признание лица нуждающимся в жилом помещении (ч. 1 ст. 51, ч. 3 ст. 91.3 ЖК РФ), которое по двум договорам производится по аналогичным основаниям, предусмотренным в ст. 51 ЖК РФ;

в). постоянное и длительное проживание в определённом населенном пункте. Следует отметить, что в федеральном жилищном законодательстве данное требование вообще отсутствует, тем не менее, субъекты РФ устанавливают свои правила. Так, в СанктПетербурге для признания лица нуждающимся в жилом помещении в целях заключения договора социального найма необходимо постоянное проживание в соответствующем городе на законных основаниях не менее десяти лет [11], в целях заключения договора некоммерческого найма - не менее пяти лет [10];

г). отнесение гражданина к определенной категории лиц, находящихся в тяжелом финансовом положении. Для двух договоров - это отдельные, специальные категории. Так, в целях заключения договора социального найма гражданин должен быть признан малоимущим. Закрепление возможности получения социального жилья малоимущими реализует требование ч. 3 ст. 40 Конституции РФ, однако, как отмечает В.Н. Литовкин, всеобщее введение данной конституционной нормы состоялось лишь с даты введения Жилищного кодекса РФ [17].

Под малоимущими понимаются граждане, если они признаны таковыми органом местного самоуправления в порядке, установленном законом соответству- 
ющего субъекта РФ, с учётом дохода, приходящегося на каждого члена семьи, и стоимости имущества, находящегося в собственности членов семьи и подлежащего налогообложению (ч. 2 ст. 49 ЖК РФ).

В случае с некоммерческим наймом, наоборот, гражданин не должен относиться к категории малоимущих, но его и постоянно проживающих совместно с ним членов его семьи доход и стоимость подлежащего налогообложению имущества не должны позволять им приобрести жилое помещение в собственность (в том числе с помощью кредитов или займов) на территории соответствующего муниципального образования. Максимальный размер дохода гражданина и стоимости имущества определяется органами местного самоуправления в порядке, установленном законом субъекта Российской Федерации (ст. 91.3 ЖК РФ).

В федеральном законодательстве для постановки гражданина на учет в целях заключения договора социального найма предусматривается ещё одно требование - несовершение гражданином в течение пяти последних лет намеренных действий, влекущих признание его нуждающимся в жилом помещении (ст. 53 ЖК).

По договору социального найма жилые помещения предоставляются гражданам по месту их жительства в границах соответствующего населенного пункта (ч. 5 ст. 57 ЖК РФ), по договору некоммерческого найма - в границах муниципального образования (в Москве, Санкт-Петербурге и Севастополе - на территории соответствующего субъекта РФ) (ч. 2 ст. 19.14, 19.15 ЖК РФ).

Рассматриваемые договоры являются возмездными. Хотя в отношении социального найма Е.А. Суханов [19, с. 400] считает, что данный договор может быть как возмездным, так и безвозмездным, если в предусмотренных законом случаях наниматель освобождается от платы за наём. Однако необходимо обратить внимание на то, что п. 9 ст. 156 ЖК РФ освобождает малоимущих граждан только от платы за наём, но не от бремени расходов на содержание, ремонт жилья и от оплаты коммунальных услуг, в этом случае договор социального найма сохраняет (хотя и в меньшей степени) возмездный характер [14, с. 54]. Плата за наём жилого помещения, а также за его содержание по договорам социального найма и найма жилых помещений государственного и муниципального жилищного фонда определяется органом местного самоуправления, а в городах федерального значения - органом государственной власти (ч. 3 ст. 156 ЖК РФ), по договору некоммерческого найма плата за наём определяется органом государственной вла- сти, местного самоуправления или же наймодателем в установленном порядке (ч. 1 ст. 156 ЖК РФ).

Договор социального найма жилого помещения является бессрочным, со все еще сохраняющимся правом бесплатной приватизации предоставленных жилых помещений, срок действия которого истекает 1 марта 2016 года (пп. 1). п. 2 ст. 2 Федерального закона «О введении в действие Жилищного кодекса РФ» от 29 декабря 2004 г. № 189-Ф3). В свою очередь, договор некоммерческого найма заключается на срок не менее чем один год, но не более чем десять лет, а права приватизации не предусматривается.

Договор найма жилого помещчения является гражданско-правовым договором, отношения по которому возникают классическим образом, т.е. на основе принципа свободы договора [16], поэтому каких-либо административно-правовых предпосылок для его заключения в ГК РФ не устанавливается, а его условия, в том числе и размер наёмной платы, по общему правилу определяются соглашением сторон. Данный договор в большей степени распространен в частном жилищном фонде. Однако также он используется и в государственном и муниципальном жилищном фондах в целях поддержки лиц в улучшении жилищных условий [8].

В Германии наём жилья с социально незащищенными категориям лиц, нуждающимися в жильё, регулируется гражданским законодательством, а также специальными законами в жилищной сфере, которые отнесены к сфере конкурирующей законодательной компетенции (п. 1 и п. 18 ст. ч. 1 ст. 74 Основного закона ФРГ), т.е. земли обладают полномочием на законодательство лишь в тех случаях, когда Федерация не пользуется своими законодательными правами.

В книге второй Германского гражданского уложения имеется глава «Наём. Аренда», в которой раздельно урегулированы вынесенные в название главы договоры, каждый из которых является самостоятельной разновидностью договоров [1, с. 652]. В части, регулирующей наём, содержится блок норм по жилищному найму, в то время как прямое указание на договор найма жилого помещения в ГГУ отсутствует. Поэтому определение договора найма жилого помещения можно дать на основании $\S 535$ подраздела 1 раздела 5 ГГУ «Общие положения об отношениях найма». Договор найма жилого помещения - это соглашение, в силу которого одна сторона - наймодатель обязуется предоставить другой стороне - нанимателю жилое помещение, в состоянии пригодном для проживания, поддерживать его в этом состоянии в течение срока найма, а также нести обременения, связанные со сданным в наём 
помещением. Наниматель же обязуется выплачивать наймодателю согласованную наёмную плату. В ГГУ также не предусмотрено какой-либо специальной статьи, регулирующей наёмные отношения с лицами, нуждающимися в жилых помещениях, однако, в § 549 ГГУ имеется упоминание о найме жилого помещения лицом публичного права и частными благотворительными организациями с тем, чтобы передать его лицам, остро нуждающимся в жильё.

Предметом договора найма жилого помещения может быть как жильё, передаваемое на условиях, определяемых соглашением сторон, так и социальное жильё, условия передачи которого определяются его целевым назначением.

Общие положения о поддержке социально незащищённых лиц в найме жилья устанавливаются в нескольких федеральных актах, из которых к основному относится Закон о содействии в обеспечении жилыми помещениями от 13 сентября 2001 года [9]. К целевой группе, которой оказывается поддержка относят семьи (хозяйства), которые не могут самостоятельно приобрести жильё, в особенности, выделяются семьи, имеющие низкий уровень доходов, и иные группы (родители-одиночки, беременные, пожилые и др.).

Лицам, имеющим низкий уровень доходов для того, чтобы заключить договор найма в социальном доме необходимо подать заявление на выдачу разрешения на пользование жилым помещением в социальном доме (“Wohnberechtigungsschein”), а после получения данного разрешения на его основании заключить с наймодателем договор найма жилого помещения в социальном доме.

Для принятия заявления от лица, нуждающегося в жилом помещении, необходимо соблюдение двух основных условий. Во-первых, проживание в Германии на законных основаниях. В отличие от России требование о наличии немецкого гражданства к потенциальному нанимателю в Германии не предъявляется, но если он является гражданином какого-либо иного государства, нежели государства-члена Европейского союза, то у него должно быть разрешение на пребывание в Германии, срок которого истекает не ранее, чем через год [24]. Во-вторых, отнесение лица к категории нуждающегося в жилом помещении, производимое на основании подсчета доходов лица за последние 12 месяцев, которые не должны превышать установленных законодательством пределов. Требования о таких пределах доходов указаны в § 9 Закона о содействии в обеспечении жилыми помещениями, однако, в нем также оговаривается возможность для правительств земель ФРГ устанавливать собственные размеры доходов, которые будут соответствовать жилищной ситуации в конкретном регионе. Например, в земле Северный Рейн-Вестфалия определены следующие границы доходов: на одного совершеннолетнего лица - 18430 евро, на двух - 22210 евро, на каждое последующее совершеннолетнее лицо прибавляется 5100 евро, а на каждое лицо до 18 лет - 660 евро [25].

Заявление подается, как правило, в жилищное управление населенного пункта соответствующей земли, в которой лицо намеревается проживать. Разрешение на пользование жилым помещением в социальном доме действует один год в пределах территории выдавшей его земли.

После выдачи разрешения будущему нанимателю органом по содействию в получении жилья могут быть представлены соответствующие варианты жилья и если ни одно из них ему не подходит, он должен сообщить об этом, обосновав причину отказа. Кроме того, гражданин вправе самостоятельно искать социальное жильё через газеты (в объявлениях о сдаче в наём жилого помещения указывается, что оно может быть передано только при наличии соответствующего разрешения) или обратившись в жилищные ассоциации и к частным наймодателям, предоставляющим социальное жильё [25].

Плата за наёмное жильё, как правило, определяется в договоре о содействии в получении социального жилья, которое заключается между компетентным органом и организацией-наймодателем. Кроме того, государством финансируется ремонт такого жилья, а его нанимателям предоставляется право на получение субсидии на наём жилья [23, с. 95-98].

Подводя итог, можно сделать вывод о том, что механизмы, реализующие право граждан на жилище в части поддержки лиц, находящихся в затруднительном финансовом положении, в России и Германии существенно различаются. Отнесение граждан, к категории лиц, имеющих право на социальное жильё, в законодательстве двух государств производится на отличных основаниях и по различным методикам, уровень же доходов (а в России это и стоимость имущества) определяется на уровне субъектов (земель) федераций. В России социальное жильё получить гораздо сложнее ввиду необходимости выполнения большего количества условий, однако, в случае с социальным наймом жильё передается нанимателю в бессрочное пользование, а с договором найма жилого помещения жилищного фонда социального использования оно может быть передано на срок до десяти лет, при этом гражданину заявлять о наличии определенного уровня дохода в течение действия данных договоров не требуется. В Германии же 
получать разрешение на наём жилого помещения в социальном доме нужно каждый год, доказывая, что уровень дохода не превышает определенного предела. В целом, представляется, что последний подход позволяет обеспечивать бо́льшее количество свободного социального жилья для семей, действительно в нем нуждающихся.

В связи с этим, при выработке социальной политики Российской Федерации в жилищном секторе, предлагается принимать во внимание некоторые нормы, имеющиеся в германском законодательстве в сфере найма социального жилья. Например, предусмотреть возможность получения социального жилья не только на территории соответствующего населенного пункта, в котором проживает гражданин, но на всей территории соответствующего субъекта. Помимо этого, руководствуясь немецкой практикой, предлагается установить на федеральном уровне единые методики подсчета дохода и минимальный уровень дохода, получая который лицо вправе претендовать на социальное жильё. При этом субъекты Российской Федерации смогли бы устанавливать свои границы размеров доходов исходя из текущей жилищной ситуации, но не ниже тех, что закреплены на федеральном уровне. Такой подход позволит упростить законодательное регулирование, а также обеспечить дополнительные права для граждан, проживающих в различных субъектах Российской Федерации.

\section{Библиография:}

1. Брагинский М.И., Витрянский В.В. Договорное право. Книга вторая: договоры о передаче имущества. 2-е изд., стер. М.: Статут, 2011. $780 \mathrm{c.}$

2. Германское гражданское уложение в ред. опубликования от 2 января 2002 года = Bürgerliches Gesetzbuch in der Fassung der Bekanntmachung vom 2. Januar 2002 / Dejure.org (juristisches Informationsportal) [Электронный pecypc]. URL: http:// dejure.org/gesetze/BGB (дата обращения: 15.01.2016).

3. Гражданский кодекс России: Договоры и другие обязательства. Текст проекта, комментарии, проблемы. Ч. 2 / Редкол.: Алексеев С.С. (Предисл.), Брагинский М.И., Витрянский В.В., Калмыков Ю.Х., Козырь О.М. (Науч. ред.), Комаров А.С., Маковский А.Л. (Науч. ред.), Суханов Е.А., Толстой Ю.К., Хохлов С.А. (Науч. ред.), Цыганенко И.Г., Шилохвост О.Ю., Яковлев В.Ф. М.: Изд-во Междунар. центра финансово-эконом. развития, 1995. С. 243-244.

4. Гражданский кодекс Российской Федерации от 26 января 1996 г. № 14-Ф3 (часть вторая) // Собрание законодательства РФ. 1996. Ст. 410.

5. Жилищные условия [Электронный ресурс]: предоставление жилых помещений / Федеральная служба государственной статистики. 2015. URL: http:/www.gks.ru/wps/wcm/connect/rosstat_main/rosstat/ru/statistics/population/housing/\# (дата обращения: 28.01.2016).

6. Жилищный кодекс Российской Федерации от 29 декабря 2004 г. № 188-Ф3 // Собрание законодательства РФ. 2005. № 1 (ч. І). Ст. 14.

7. Жильё в России арендуют в 2-4 раза реже, чем в США и Европе [Электронный ресурс]: аналитика / М. Заблудовская. «РИА Недвижимость». М., 2013. URL: http://riarealty.ru/analysis_trends/20130320/399955909.html (дата обращения: 28.01.2016).

8. Закон города Москвы от 27 января 2010 года № 2 «Основы жилищной политики города Москвы» // Ведомости Московской городской Думы. 2010. № 2. Ст. 2.

9. Закон о содействии в обеспечении жилыми помещениями от 13 сентября 2001 года = Gesetz über die soziale Wohnraumförderung // Bundesgesetzblatt. I. S. 2376.

10. Закон Санкт-Петербурга от 13 июля 2015 года № 475-92 «О жилых помещениях жилищного фонда социального использования и о наемных домах социального использования» // Вестник Законодательного Собрания СанктПетербурга. № 24. 2015. Доступ из справ. - правовой системы «Консультант Плюс».

11. Закон Санкт-Петербурга от 19 июля 2005 г. № 407-65 «О порядке ведения учета граждан в качестве нуждающихся в жилых помещениях и предоставлении жилых помещений по договорам социального найма в Санкт-Петербурге» // Вестник Администрации Санкт-Петербурга. № 8. 2005. Доступ из справ. - правовой системы «Консультант Плюс».

12. Иванчак А.И. Гражданское право Российской Федерации [Электронный ресурс] : Особенная часть. М.: Статут, 2014. С. 81. Доступ из справ. - правовой системы «Консультант Плюс».

13. Конституция Российской Федерации (принята на всенародном голосовании 12 декабря 1993 г.) // Собрание законодательства РФ. 2014. № 31. Ст. 4398.

14. Копылов А.В., Никитина В.А. Особенности договоров социального найма жилых помещений с малоимущими гражданами в Москве и Санкт-Петербурге // Журнал «Законодательство». 2012. № 8. С. 54.

15. Крашенинников П.В. Наем жилого помещения (гл. 35) // Комментарий к Гражданскому кодексу Российской Федерации (часть вторая) / Под ред. О.М. Козырь, А.Л. Маковского, С.А. Хохлова, М.: МЦФЭР, 1996. С. 78. Доступ из справ. правовой системы «Консультант Плюс».

16. Литовкин В.Н. Жилищное законодательство и концепция развития гражданского законодательства [Электронный ресурс] // Журнал российского права. 2010. № 1. С. 45. Доступ из справ. - правовой системы «Консультант Плюс».

17. Литовкин В.Н. Конституционное право российских граждан на жилище [Электронный ресурс] / Е.А. Павлова, О.Ю. Шилохвост. Актуальные вопросы российского частного права / Сборник статей, посвященный 80-летию со 
дня рождения профессора В.А. Дозорцева, 2008. C. 43. URL: http://scibook.net/periodika-sborniki-yuridicheskaya/ konstitutsionnoe-pravo-rossiyskih-grajdan-16136.html (дата обращения: 28.01.2016).

18. Основной закон Федеративной Республики Германия от 23 мая 1949 года = Grundgesetz für die Bundesrepublik Deutschland [Электронный pecypc]. URL: https://www.bundestag.de/grundgesetz (дата обращения: 30.01.2016).

19. Российское гражданское право: Учебник. В 2-х томах. Т. ІІ: Обязательственное право / Отв. ред. Е.А. Суханов. М.: Статут, 2010. $1208 \mathrm{c}$

20. Седугин П.И. Жилищное право. 2-е изд., перераб. и доп. М.: НОРМА, 2003. С. 89.

21. Das Recht auf Wohnen - ein Menschenrecht auch in Deutschland. // M. Krennerich / Nürnberger Menschenrechtszentrum. 2013. [Электронный ресурc]. URL: http://www.menschenrechte.org/lang/de/wsk-rechte/das-recht-auf-wohnen-ein-menschenrechtauch-in-deutschland (дата обращения: 28.01.2016).

22. General Comment No. 4 [Электронный ресурс]: the Right to Adequate Housing (Art. 11 (1) of the Covenant) / UN Committee on Economic, Social and Cultural Rights. 1991. URL: http://www.refworld.org/docid/47a7079a1.html (дата обращения: 28.01.2016).

23. Whitehead C., Scanlon K. Social Housing in Europe. London School of Economics and Political Science. London, 2007. P. $95-98$.

24. Wohnberechtigungsschein-WBS-Antragsannahme/BerlinOnline Stadtportal. [Электронный pecypc]. URL: https://service. berlin.de/dienstleistung/120671/ (дата обращения: 15.01.2016).

25. Wohnberechtigungsschein (WBS) / Stadt Köln. [Электронный ресурc]. URL: http://www.stadt-koeln.de/service/produkte/ wohnberechtigungsschein\# (дата обращения: 15.01.2016).

\section{References (transliterated):}

1. Braginskii M.I., Vitryanskii V.V. Dogovornoe pravo. Kniga vtoraya: dogovory o peredache imushchestva. 2-e izd., ster. M.: Statut, 2011. $780 \mathrm{~s}$.

2. Ivanchak A.I. Grazhdanskoe pravo Rossiiskoi Federatsii [Elektronnyi resurs] : Osobennaya chast'. M.: Statut, 2014. S. 81. Dostup iz sprav. - pravovoi sistemy «Konsul'tant Plyus».

3. Kopylov A.V., Nikitina V.A. Osobennosti dogovorov sotsial'nogo naima zhilykh pomeshchenii s maloimushchimi grazhdanami v Moskve i Sankt-Peterburge // Zhurnal «Zakonodatel'stvo». 2012. № 8. S. 54.

4. Krasheninnikov P.V. Naem zhilogo pomeshcheniya (gl. 35) // Kommentarii k Grazhdanskomu kodeksu Rossiiskoi Federatsii (chast' vtoraya) / Pod red. O.M. Kozyr', A.L. Makovskogo, S.A. Khokhlova, M.: MTsFER, 1996. S. 78. Dostup iz sprav. pravovoi sistemy «Konsul'tant Plyus».

5. Litovkin V.N. Zhilishchnoe zakonodatel'stvo i kontseptsiya razvitiya grazhdanskogo zakonodatel'stva [Elektronnyi resurs] // Zhurnal rossiiskogo prava. 2010. № 1. S. 45. Dostup iz sprav. - pravovoi sistemy «Konsul’tant Plyus».

6. Litovkin V.N. Konstitutsionnoe pravo rossiiskikh grazhdan na zhilishche [Elektronnyi resurs] / E.A. Pavlova, O.Yu. Shilokhvost. Aktual'nye voprosy rossiiskogo chastnogo prava / Sbornik statei, posvyashchennyi 80-letiyu so dnya rozhdeniya professora V.A. Dozortseva, 2008. S. 43. URL: http://scibook.net/periodika-sborniki-yuridicheskaya/konstitutsionnoe-pravo-rossiyskihgrajdan-16136.html (data obrashcheniya: 28.01.2016).

7. $\quad$ Sedugin P.I. Zhilishchnoe pravo. 2-e izd., pererab. i dop. M.: NORMA, 2003. S. 89.

8. Whitehead S., Scanlon K. Social Housing in Europe. London School of Economics and Political Science. London, 2007. P. $95-98$. 